\title{
Frailty and food insecurity in older adults
}

\author{
Mario Ulises Pérez-Zepeda ${ }^{1}$, Roberto Carlos Castrejón-Pérez ${ }^{1}$, Emma Wynne-Bannister ${ }^{2}$ \\ and Carmen García-Peña ${ }^{3, *}$ \\ ${ }^{1}$ Geriatric Epidemiology Research Department, Instituto Nacional de Geriatría, Mexico City, Mexico: ${ }^{2}$ Public Health \\ Division, Universidad Nacional Autónoma de México, Mexico City, Mexico: ${ }^{3}$ Instituto Nacional de Geriatría, \\ Periférico Sur 2767, Colonia San Jerónimo Lídice, Delegación Magdalena Contreras, CP 10200, México DF, México
}

Submitted 27 June 2015: Final revision received 25 March 2016: Accepted 31 March 2016: First published online 2 May 2016

\begin{abstract}
Objective: The objective of the current work was to determine the association between food insecurity and frailty in older adults, within the context of a country with accelerated ageing and nutritional problems.

Design: Cross-sectional analysis of a representative nationwide survey on health and nutrition.

Setting: Mexican nationwide survey.

Subjects: A sample of 7108 adults aged 60 years or older living in communities, representative of Mexican older adults.

Results: Multivariate regression and descriptive analyses of food insecurity and frailty were performed. From a total of 7108 adults aged 60 years or older, with a mean age of 70.7 years, most ( $54.7 \%)$ were women. Food security categories were: $26.3 \%$ had food security, $40.3 \%$ had mild food insecurity, $20.5 \%$ had moderate food insecurity and $12.9 \%$ had severe food insecurity. Food insecurity categories were associated with frailty, with the severe category having the highest odds ratio of $2 \cdot 41$ (95\% CI 2.03, 2.86; $P<0.001$ ) after adjustment for confounding factors.

Conclusions: According to our results, food insecurity is associated to frailty, which in turn is a condition that renders the older adult at a higher risk of developing adverse outcomes. Targeted food programmes for older adults with a high risk of having food insecurity or of being frail may improve health in this population group.
\end{abstract}

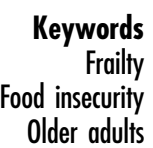

Keywords

Older adults
Low- and middle-income countries still face problems related to malnutrition and obesity as well as those related to ageing $^{(1)}$. Along with infectious diseases, maternal conditions and nutritional disorders, the accelerated ageing of the population impacts both public and individual health ${ }^{(2,3)}$.

Food security - defined by the FAO as a 'situation that exists when all people, at all times, have physical, social and economic access to sufficient, safe and nutritious food that meets their dietary needs and food preferences for an active and healthy life' - has been increasingly important to the health of older adults currently living in low- and middle-income countries ${ }^{(4)}$. Food insecurity and its effects on nutrition deeply impact the overall well-being of aged people, mainly through frailty and functional impairments that could in turn lead to dependency ${ }^{(5,6)}$. A number of reports have established the deleterious effects of food insecurity on nutritional status of the elderly ${ }^{(7,8)}$. For example, a recent report showed that food insecurity is related to obesity and chronic diseases in this age group $^{(9,10)}$. Moreover, malnutrition and obesity are related to oral health problems, gastrointestinal disorders and anorexia, which in turn are related to diabetes and hypertension, two of the most common chronic diseases of this age group ${ }^{(1)}$.

Frailty is a condition that renders the older adult vulnerable to stressors and prone to adverse outcomes. For example, if a frail older adult has a cold, he or she will have an increased probability of contracting pneumonia. Frailty is a continuously growing and recognized phenomenon, both in research and clinical settings, due to its increased demand on health services and its impact on the family (burden) ${ }^{(11-13)}$. Its predictive value for adverse outcomes has been substantially evidenced ${ }^{(14)}$ in comparison to the lack of knowledge on risk factors that could precede it, not only health-related but also socio-economic determinants. Having more information could improve the care of older adults who suffer from this condition ${ }^{(15,16)}$.

Food insecurity has been studied among older adults in different settings and a consistent association with poorer health has been reported ${ }^{(10,17)}$. However, this problem has improved with food programmes that not only ameliorate the availability of food but also increase diet variability ${ }^{(18)}$ (currently not available for older adults in Mexico). 
Recent evidence suggests that there is a link between frailty and nutritional disorders ${ }^{(6,19)}$ and consequently with disability ${ }^{(20)}$. The role of low protein intake and possibly vitamin $\mathrm{E}$ along with a persistent inflammatory status seem to be part of this path ${ }^{(5,8,20,21)}$. On the other hand, food insecurity as a social determinant of frailty has been poorly studied in older adults, in particular in low- and middleincome countries, where social disparities are more common. Data regarding food insecurity in Mexico have shown that older adults have a higher prevalence than expected (67\%). An asociation between food insecurity and low weight was found ${ }^{(22)}$.

The aim of the present work was to determine if an association between frailty and food insecurity exists in a nationwide survey of Mexican older adults. We hypothesized that older adults with higher food insecurity would also have a higher frailty burden.

\section{Methods}

The present study is a cross-sectional analysis of the 2012 Mexican Survey on Nutrition and Health (ENSANUT; Encuesta Nacional de Salud y Nutrición). The 2012 ENSANUT had a sample of 96031 individuals, including a representative sample of older adults with specific questions and tests to assess their health, such as depressive symptoms, activities of daily living, cognitive assessment, falls and gait speed, among others. Older adults (aged 60 years or older) who were the head of household were included in the current analysis. The description of the 2012 ENSANUT in its entirety is available elsewhere $^{(23)}$.

For the study of frailty, Rockwood et al.'s frailty index was used, in which a higher score indicates a higher frailty status, and was integrated, as Searle et al. indicate, with forty-four deficits from different dominions excluding those that could be present in early life ${ }^{(24)}$. Deficits included memory complaints, dependence (activities of daily living), depressive symptoms, co-morbidities, violence or accident-related health problems, hearing and vision impairment, nutritional conditions, physical performance tests, self-esteem and satisfaction with life. Each one of the deficits was given a score between 0 and 1 (the majority of deficits are dichotomous but some are distributed into more than two categories). Each individual's deficit score was added and divided by all deficits taken into account ( $n$ 44), giving a total theoretical frailty score ranging from 0 to 1 (considered to be theoretical since scores nearing 1 are seen to be incompatible with life; see online supplementary material, Supplemental Table 1). The frailty index was further divided into those with a score $\geq 0.21$ and those with $<0 \cdot 21$, the first group being considered frail. This cut-off value has already been validated in Mexican older adults; those with frailty index score $\geq 0 \cdot 21$ have higher mortality risk ${ }^{(25)}$.
Food insecurity was assessed with the previously validated questionnaire ELCSA (Encuesta Latinoamericana $y$ del Caribe de Seguridad Alimentaria; Caribbean and Latin-American Survey on Food Security $)^{(22,26,27)}$. Only the head of the family answered this questionnaire and it represents household-level food insecurity. The ELCSA questionnaire is composed of two sections, the first related to adults and the second to individuals younger than 18 years $^{(22)}$. The first section is composed of eight questions that start with the sentence: 'In the last 3 months, due to lack of money or other resources, did you or any other adult in this household ...' followed by eight different questions. For older adults with an 18-year-old or younger person living in the same household, there are seven additional questions, with a different beginning: 'In the last 3 months, due to lack of money or other resources, did any 18-year or younger person living in this household ...' followed by the rest of the question. One point was given for each question answered 'yes', the higher the score the higher food insecurity. Further categorization of food insecurity according to the final score was defined as: none (score $=0)$, mild (score $=1-5$ for the complete questionnaire or score $=1-3$ for the adult-only questionnaire), moderate (score $=6-10$ for the complete questionnaire or score $=4-6$ for the adult-only questionnaire) and severe (score $=11-15$ for the complete questionnaire or score $=7-8$ for the adult-only questionnaire) ${ }^{(22)}$.

Other variables assessed were age, sex, education (none, primary school, high school, college and postgraduate), marital status, urban stratus (living in a location with 7500 habitants or higher), self-reported speaking of an indigenous language, smoking (never smoked, fewer than 100 cigarettes, at least 100 cigarettes in life) and alcohol consumption (drinking five or more alcoholic beverages at least once weekly). To take into account income, a composite variable for the total monthly income of the household members was estimated, regardless if the income was from obtained from work or from other sources; this variable is in pesos, reference values for \$US equivalence in 2012 are provided.

A complete description stratified by sex was carried out, with means and standard deviations for continuous variables, and frequencies for nominal variables. Bivariate analyses using the $\chi^{2}$ test between categories of frailty index score (the lower the score the lower the frailty burden and vice versa) and each of the items of the ELCSA, in addition to the severity categories (for the whole test scores) were done to test the differences.

A multivariate analysis (multiple logistic regression) was performed between the categories of the frailty index and the food insecurity severity categories (with food security as the reference category). Unadjusted and adjusted multiple logistic regression models controlling for confounding variables were added: age, sex, marital status, urban stratus, speaking indigenous language, 
household income, smoking status and current alcohol drinking. In order to show if estimates changed, a thirtynine-item frailty index was constructed, excluding nutrition-related items, to fit the model just like the fortyfour-item frailty index, and is presented in the online supplementary material. In addition, estimates were also run with 212 older adults from the sample who were not head of the household (data available upon request).

\section{Results}

From the total population, 7108 adults aged 60 years or older were considered head of the household. The mean age was 70.7 (SD 8.1) years, with a predominance of women $(54.7 \%)$. Of all the levels of education, primary represented $55.4 \%$ ( $n$ 3940). The majority of the older adults included in the analysis were married, $55.4 \%$ ( $n$ 3942). Older adults living in an urban stratus represented $61.1 \%(n$ 4347), and up to $12 \cdot 7 \%$ ( $n$ 908) spoke an indigenous language. The mean monthly estimated income for the household was 795.12 (sD 2553.83) Mexican pesos (average equivalence in 2012 was 1 \$US $=13 \cdot 16$ Mexican pesos).

Those who never smoked comprised 53.2\% ( $n$ 3788) and $35.8 \%$ ( $n$ 2545) smoked at least 100 cigarettes in their lives. Of the total population, $2 \cdot 5 \%$ reported alcohol consumption in the last week (see Table 1). Regarding food security categories: $26 \cdot 3 \%$ had food security, $40 \cdot 3 \%$ mild food insecurity, $20.5 \%$ moderate food insecurity and $12.9 \%$ severe food insecurity.

For the frailty index, descriptive statistics were as follows: score mean was 0.201 (SD 0.09), with $45.2 \%$ having a score $\geq 0 \cdot 21$. The deficit with the highest mean was $\mathrm{Hb}(0.572)$ and the lowest was having suffered aggression in the last year (0.014). Mean of the frailty index for each food insecurity category was as follows: secure 0.194 (SD 0.09), mild 0.214 (SD 0.094), moderate 0.228 (SD 0.094) and severe 0.237 (SD 0.097), with a significance of 0.076 ( $F$ statistic for linear trend 0.03 ).

From the total of households, 1801 had people 18 years old or younger living with them; therefore the complete ELCSA questionnaire was considered (fifteen items; (Table 2). In the bivariate analysis, all of the ELCSA items were significantly different between older adults with a frailty index $\geq 0 \cdot 21$ or $<0 \cdot 21$, with the exception of five items from the last seven questions (only for households with 18-year-olds or younger persons). Regarding categories of food insecurity, the proportion of older adults with frailty index score $\geq 0.21$ increased as follows: secure $36 \cdot 10 \%$, mild food insecurity $43.99 \%$, moderate food insecurity $52 \cdot 19 \%$ and severe food insecurity $56 \cdot 20 \%$ $(P<0 \cdot 001$; Table 2).

Multiple logistic regression models were significant for all categories, when compared with the reference (food security). Mild food insecurity unadjusted OR was 1.39 (95\% CI 1.23, 1.56; $P<0.001)$ and 1.46 (95\% CI 1.28, 1.66; $P<0.001)$ for adjusted OR. In the case of moderate food

Table 1 General characteristics, stratified by sex, of the representative sample of community-dwelling Mexican adults aged 60 years or older, 2012 Mexican Survey on Nutrition and Health (ENSANUT; Encuesta Nacional de Salud y Nutrición)

\begin{tabular}{|c|c|c|c|c|c|c|}
\hline & \multicolumn{2}{|c|}{ Total $(n 7164)^{*}$} & \multicolumn{2}{|c|}{ Men ( $n 3241 ; 45.2 \%)$} & \multicolumn{2}{|c|}{ Women (n 3923; 54.7\%) } \\
\hline & Mean or $n$ & SD or\% & Mean or $n$ & SD or \% & Mean or $n$ & SD or $\%$ \\
\hline Age (years), mean and SD & $70 \cdot 7$ & $8 \cdot 1$ & $70 \cdot 8$ & 8.0 & $70 \cdot 6$ & $8 \cdot 1$ \\
\hline \multicolumn{7}{|l|}{ Educationt, $n$ and $\%$} \\
\hline None & 2157 & $30 \cdot 3$ & 844 & $39 \cdot 1$ & 1313 & $60 \cdot 8$ \\
\hline Primary school & 3940 & $55 \cdot 4$ & 1833 & $46 \cdot 5$ & 2107 & $53 \cdot 4$ \\
\hline High school & 722 & $10 \cdot 2$ & 339 & 46.9 & 383 & $53 \cdot 0$ \\
\hline College or higher & 289 & $4 \cdot 1$ & 196 & $67 \cdot 8$ & 93 & $32 \cdot 1$ \\
\hline Married $\dagger, n$ and $\%$ & 3942 & $55 \cdot 4$ & 2264 & $57 \cdot 4$ & 1678 & 42.5 \\
\hline Urban, $n$ and \% & 4347 & $61 \cdot 1$ & 1863 & $42 \cdot 8$ & 2484 & $57 \cdot 1$ \\
\hline Indigenous, $n$ and $\%$ & 908 & $12 \cdot 7$ & 426 & $46 \cdot 9$ & 482 & $53 \cdot 1$ \\
\hline Estimated monthly income $\neq, \mp$, mean and SD & $795 \cdot 12$ & $2553 \cdot 83$ & $1237 \cdot 00$ & 3254.88 & $430 \cdot 71$ & 1694.90 \\
\hline Children living in household, $n$ and $\%$ & 1801 & $25 \cdot 3$ & 819 & 45.4 & 982 & 54.5 \\
\hline \multicolumn{7}{|l|}{ Smoking statust, $n$ and \% } \\
\hline Never smoked & 3788 & $53 \cdot 2$ & 809 & $21 \cdot 3$ & 2979 & $78 \cdot 6$ \\
\hline Smoked fewer than 100 cigarettes in life & 775 & $10 \cdot 9$ & 444 & $57 \cdot 2$ & 331 & $42 \cdot 7$ \\
\hline Smoked at least 100 cigarettes in life & 2545 & $35 \cdot 8$ & 1959 & $57 \cdot 3$ & 589 & $23 \cdot 0$ \\
\hline $\begin{array}{l}\text { Drinking five or more alcoholic beverages } \\
\text { at least once weeklyt, } n \text { and \% }\end{array}$ & 176 & 2.5 & 147 & 83.5 & 29 & $16 \cdot 5$ \\
\hline \multicolumn{7}{|l|}{ Food insecurity categoryt, $n$ and \% } \\
\hline Secure & 1868 & $26 \cdot 3$ & 880 & $47 \cdot 1$ & 988 & $52 \cdot 8$ \\
\hline Mild & 2864 & $40 \cdot 3$ & 1302 & $45 \cdot 4$ & 1562 & 54.5 \\
\hline Moderate & 1457 & 20.5 & 614 & $42 \cdot 1$ & 843 & $57 \cdot 8$ \\
\hline Severe & 919 & 12.9 & 416 & $45 \cdot 2$ & 503 & $54 \cdot 7$ \\
\hline Frailty index $\geq 0.21 \dagger, n$ and $\%$ & 3213 & $45 \cdot 2$ & 1190 & $37 \cdot 0$ & 2023 & 51.9 \\
\hline
\end{tabular}

${ }^{*}$ Percentages for totals are for the column, percentages for men and women are for the lines.

$\dagger P<0.001$ for the comparison between men and women.

$\ddagger$ Estimated income is in Mexican pesos. The average equivalence in 2012 was 1 \$US $=13 \cdot 16$ Mexican pesos. 
Table 2 Bivariate analyses of positive answers to food insecurity questionnaire items and the frailty index score among the representative sample of community-dwelling Mexican adults aged 60 years or older, 2012 Mexican Survey on Nutrition and Health (ENSANUT; Encuesta Nacional de Salud y Nutrición)

\begin{tabular}{|c|c|c|c|c|c|}
\hline & \multicolumn{2}{|c|}{ Frailty index $\geq 0.21$} & \multicolumn{2}{|c|}{ Frailty index $<0.21$} & \multirow[b]{2}{*}{$P$ value } \\
\hline & $n$ & $\%$ & $n$ & $\%$ & \\
\hline \multicolumn{6}{|c|}{ 'In the last 3 months, due to lack of money or other resources, did you or any other adult in this household ..."* } \\
\hline '... were worried because of shortage of food?' & 2205 & 68.63 & 2239 & 57.48 & $<0.001$ \\
\hline '... run out of food?' & 948 & 29.51 & 824 & $21 \cdot 16$ & $<0.001$ \\
\hline '... not have a healthy, nutritive or balanced diet?' & 1666 & 51.85 & 1664 & $42 \cdot 72$ & $<0.001$ \\
\hline '... have a diet with a poor variety?' & 1824 & $56 \cdot 77$ & 1815 & $46 \cdot 6$ & $<0.001$ \\
\hline '... skip breakfast, lunch or dinner?' & 822 & 25.58 & 703 & 18.05 & $<0.001$ \\
\hline '... eat less than you should?' & 1182 & $36 \cdot 79$ & 1030 & 26.44 & $<0.001$ \\
\hline '... were hungry but not eat?' & 833 & 25.93 & 693 & $17 \cdot 79$ & $<0.001$ \\
\hline '... just eat once a day or skip an entire day?' & 600 & 20.54 & 531 & 13.63 & $<0.001$ \\
\hline \multicolumn{6}{|c|}{ 'In the last 3 months, due to lack of money or other resources, did any 18 -year or younger person living in this household ...' $\dagger$} \\
\hline '... was left without a healthy, balanced, or nutritive diet?' & 312 & $37 \cdot 37$ & 309 & 31.99 & 0.049 \\
\hline '... had a diet based on scarce variety of food?. & 352 & $42 \cdot 16$ & 349 & $36 \cdot 13$ & 0.018 \\
\hline '... had to skip breakfast, lunch or dinner?' & 135 & $16 \cdot 17$ & 144 & 14.91 & 0.645 \\
\hline '... had to eat less than he/she should?/ & 197 & 23.95 & 202 & 20.91 & 0.392 \\
\hline '... had to reduce the quantity of served meals?' & 224 & $26 \cdot 83$ & 218 & 22.57 & 0.102 \\
\hline '... was hungry but did not eat?' & 119 & $14 \cdot 25$ & 119 & 12.32 & 0.335 \\
\hline '... only ate once in a day or did not eat at all?' & 93 & $11 \cdot 14$ & 99 & 10.25 & 0.706 \\
\hline \multicolumn{6}{|l|}{ Food insecurity category $\ddagger$} \\
\hline Secure & 679 & $36 \cdot 10$ & 1202 & 63.90 & $<0.001$ \\
\hline Mild & 1236 & 43.99 & 1574 & 56.01 & \\
\hline Moderate & 786 & $52 \cdot 19$ & 720 & 47.81 & \\
\hline Severe & 512 & $56 \cdot 20$ & 399 & 43.80 & \\
\hline
\end{tabular}

${ }^{\star}$ These questions were asked of all older adults $(n 7108)$.

†These questions were asked only of older adults with an 18-year-old or younger person living in the same household ( $n$ 1801; $25.34 \%$ ). †Percentages are for frail and non-frail.

insecurity, unadjusted OR was $1.93(95 \%$ CI $1 \cdot 68,2 \cdot 12$ $P<0.001)$ and 2.02 (95\% CI $1.74,2.35 ; P<0.001)$ for adjusted OR. Finally, severe food insecurity unadjusted OR was 2.27 (95\% CI $1.93,2.66 ; P<0.001)$ and $2.41(95 \% \mathrm{CI}$ 2.03, 2.86; $P<0 \cdot 001$ ) for adjusted OR (Table 3). Estimates did not change substantially with the thirty-nine-item frailty index (see online supplementary material, Supplemental Table 2).

\section{Discussion}

The aim of the current analysis was to determine if there was an association of food insecurity with frailty and according to our study an association was found. As far as we know, the present study is the first to describe this association in Latin American older adults ${ }^{(12,28)}$. Our results showed that the prevalence of food insecurity among households with older persons is very high and represents $73.8 \%$ of the total sample. The frequencies of the food insecurity categories are similar to those reported by Rivera-Márquez et al. and are considered to be worse when compared with other countries ${ }^{(22)}$. Also, our study revealed an incremental association between the frailty index score and the categorization of the ELCSA food insecurity questionnaire that is independent of other confounding variables. As shown in our results in the multivariate analyses, the probability of having a score $\geq 0.21$ in the frailty index is 1.46 times for the group with mild food insecurity, 2.02 for the group with moderate food insecurity and 2.41 times for the group with severe food insecurity; this shows an incremental and independent association between frailty and food insecurity. Severity of food insecurity is associated with higher probability of being considered frail when compared with those older adults with food security; in addition, this association is independent of other factors that have been also associated with frailty, as previously described in Mexican older adults. Having a frailty index score $\geq 0 \cdot 21$ increases mortality risk of the individual ${ }^{(25,29)}$, therefore as the severity of food insecurity increases so does the probability of getting frail and the risk of mortality.

Key factors that may aggravate the level of food insecurity are out-of-pocket health expenses and unexpected medical bills, particularly when referring to old people. A particular factor is how the older adults experience food insecurity and the skills they could use to obtain and prepare appropriate foods ${ }^{(7,30)}$. Nevertheless, in a family with chronic poverty, it is possible that neither food nor adequate health services are affordable. Bhargava et al. found that those with food insecurity have lower outof-pocket expenses ${ }^{(17)}$. Both are explained by the limited financial resources for such expenses and are indicators of the effects of poverty. Although it is possible that food insecurity among older people is different from that of other age groups, due to different health conditions of each group; notwithstanding, some research points to the fact that either children and adults have lower physical 
Table 3 Unadjusted and adjusted ${ }^{\star}$ multiple logistic regression models for frailty index $\dagger$ as the dependent variable and food insecurity categories as the independent variables (with food security as the reference) among the representative sample of community-dwelling Mexican adults aged 60 years or older, 2012 Mexican Survey on Nutrition and Health (ENSANUT; Encuesta Nacional de Salud y Nutrición)

\begin{tabular}{|c|c|c|c|c|c|c|}
\hline \multirow[b]{2}{*}{ Food insecurity category } & \multicolumn{3}{|c|}{ Unadjusted } & \multicolumn{3}{|c|}{ Adjusted } \\
\hline & OR & $95 \% \mathrm{Cl}$ & $P$ value & OR & $95 \% \mathrm{Cl}$ & $P$ value \\
\hline Secure & \multicolumn{2}{|c|}{ Reference } & - & \multicolumn{2}{|c|}{ Reference } & - \\
\hline Mild & 1.39 & $1.23,1.56$ & $<0.001$ & 1.46 & $1.28,1.66$ & $<0.001$ \\
\hline Moderate & 1.93 & $1.68,2.12$ & $<0.001$ & 2.02 & $1 \cdot 74,2 \cdot 35$ & $<0.001$ \\
\hline Severe & 2.27 & $1.93,2.66$ & $<0.001$ & 2.41 & $2 \cdot 03,2 \cdot 86$ & $<0.001$ \\
\hline
\end{tabular}

${ }^{*}$ Adjusted for age, sex, marital status, urban stratus, speaking indigenous language, household income, smoking status and current alcohol drinking. †Frailty index score $\geq 0.21$ and frailty index score $<0.21$.

activity when facing food insecurity ${ }^{(31)}$. On the other hand, it is possible to go from having food security during childhood to having food insecurity during adulthood. It is also possible that social mobility exists from poverty to wealth. Evidence shows that economic mobility is weak in Mexico, particularly in sectors of chronic and extreme poverty ${ }^{(32)}$.

Reports show that strong communities and social networks are protective factors that can be of support to old people, not only financially, but also with things such as transportation and preparing meals, among others ${ }^{(7,30)}$. This points to the fact that strategies to ameliorate the availability of food for older adults are needed. There is a need for including social dynamics into the study of frailty, as well as to more deeply explore its potential protective role among the aged. There is evidence on how nutritional conditions impact older adults' health and in particular frailty status ${ }^{(6,20,21)}$.

The current analysis is cross-sectional; there is a need for longitudinal studies exploring the role of the exposure time to food insecurity, in order to study the causal association between developing frailty and its consequences. A hypothetical path from food insecurity to frailty would be: low-protein/high-carbohydrate diets leading to muscle mass loss/obesity, leading to sarcopenia/obese sarcopenia, leading to frailty, leading to disability/death/institutionalization ${ }^{(6,8,21)}$. This path should take into consideration the exposure time, since a long time with reduced nutritional intake and lower diet variability may also lead to physiological imbalance, with its subsequent lower response to stressors. This is a vicious cycle that could be broken by reinforcing strategies to enhance food security in poor households.

On the other hand, programmes such as Meals on Wheels also ameliorate the impact of food insecurity on older adults ${ }^{(33)}$. Nevertheless, in middle-income countries such as the one from this report, a targeted and not generalized intervention to ameliorate food security could diminish the progression to disability. Currently a government programme aims to 'eliminate hunger' in all the population, without targeting or including the particular needs of older adults, which may not be helpful. Nowadays there is no evaluation of the impact on older adults of this recent food programme ${ }^{(34,35)}$. In addition, there is uncertainty on how help-seeking behaviours would be in Mexican older adults when food programmes are available; these behaviours seem to be rather complex in the older adult population ${ }^{(36)}$.

One of the main limitations of our study is the lack of information on how long the older adult has had food insecurity. There is no certainty that food insecurity has been present long enough to produce nutritional derangements, that in turn has become a symptom or deficit due to a continuous bad diet. Further studies aimed at untangling these trajectories - food insecurity, nutritional deficit, physical impact and disability - could shed light on how these interactions take place and how an intervention strategy could be implemented to break the cycle.

There is evidence that an appropriate diet could improve the health of frail older adults; however, it is not clear if this condition in itself is associated with frailty. This could give a different perspective and shift the paradigm towards the prevention of frailty, and not only the treatment of its consequences ${ }^{(6,18,20,21,37)}$.

There is an increasing need for recognizing all aspects that could shape ageing in a complex society where older adults are not necessarily included. Older adults with food insecurity have worse health conditions (such as frailty) and may develop adverse outcomes as a result, making their inclusion in modern societies even more difficult. Closing the gap in knowledge regarding determinants of ageing is the beginning of an age-inclusive world.

\section{Acknowledgements}

Financial support: This research received no specific grant from any funding agency in the public, commercial or notfor-profit sectors. Conflict of interest: None. Authorship: M.U.P.-Z. had the original idea, ran the analyses, wrote the first draft and reviewed the final manuscript. R.C.C.-P. reviewed and wrote the final manuscript. E.W.-B. reviewed, proofread and wrote the final manuscript. C.G.-P. supervised data analyses, wrote drafts and reviewed the final manuscript. Ethics of buman subject 
participation: This study was conducted according to the guidelines laid down in the Declaration of Helsinki and all procedures involving human subjects were approved by the ethics committee of the National Institute of Public Health in Mexico. All participants signed written informed consent.

\section{Supplementary material}

To view supplementary material for this article, please visit http://dx.doi.org/10.1017/S1368980016000987

\section{References}

1. Cordova-Villalobos JA, Barriguete-Melendez JA, Lara-Esqueda A et al. (2008) Chronic non-communicable diseases in Mexico: epidemiologic synopsis and integral prevention. Salud Publica Mex 50, 419-427.

2. Gutierrez-Robledo LM (2002) Looking at the future of geriatric care in developing countries. J Gerontol A Biol Sci Med Sci 57, M162-M167.

3. Sousa RM, Ferri CP, Acosta D et al. (2009) Contribution of chronic diseases to disability in elderly people in countries with low and middle incomes: a 10/66 Dementia Research Group population-based survey. Lancet 374, 1821-1830.

4. Food and Agriculture Organization of the United Nations, International Fund for Agricultural Development \& World Food Programme (2014) The State of Food Insecurity in the World 2014. Strengthening the Enabling Environment for Food Security and Nutrition. Rome: FAO.

5. Lee JS \& Frongillo EA Jr (2001) Factors associated with food insecurity among US elderly persons: importance of functional impairments. J Gerontol B Psychol Sci Soc Sci 56, S94-S99.

6. Bartali B, Frongillo EA, Bandinelli S et al. (2006) Low nutrient intake is an essential component of frailty in older persons. J Gerontol A Biol Sci Med Sci 61, 589-593.

7. Wolfe W, Olson C, Kendall A et al. (1996) Understanding food insecurity in the elderly: a conceptual framework. J Nutr Educ 28, 92-100.

8. Lee JS \& Frongillo EA Jr (2001) Nutritional and health consequences are associated with food insecurity among US elderly persons. J Nutr 131, 1503-1509.

9. Tanumihardjo S, Anderson C, Kaufer-Horwitz M et al. (2007) Poverty, obesity, and malnutrition: an international perspective recognizing the paradox. J Am Diet Assoc 107, 1966-1972.

10. Seligman H, Laraia B \& Kushel M (2010) Food insecurity is associated with chronic disease among low-income NHANES participants. J Nutr 140, 304-310.

11. Fried LP, Tangen CM, Walston J et al. (2001) Frailty in older adults: evidence for a phenotype. J Gerontol A Biol Sci Med Sci 56, M146-M156.

12. Fried LP, Ferrucci L, Darer J et al. (2004) Untangling the concepts of disability, frailty, and comorbidity: implications for improved targeting and care. J Gerontol A Biol Sci Med Sci 59, 255-263.

13. Rockwood K \& Hubbard R (2004) Frailty and the geriatrician. Age Ageing 33, 429-430.

14. Xue QL (2011) The frailty syndrome: definition and natural history. Clin Geriatr Med 27, 1-15.

15. Moreira VG \& Lourenco RA (2013) Prevalence and factors associated with frailty in an older population from the City of Rio de Janeiro, Brazil: the FIBRA-RJ Study. Clinics (Sao Paulo) 68, 979-985.

16. Walston J, Hadley EC, Ferrucci L et al. (2006) Research agenda for frailty in older adults: toward a better understanding of physiology and etiology: summary from the American Geriatrics
Society/National Institute on Aging Research Conference on Frailty in Older Adults. J Am Geriatr Soc 54, 991-1001.

17. Bhargava V, Lee JS, Jain R et al. (2012) Food insecurity is negatively associated with home health and out-of-pocket expenditures in older adults. J Nutr 142, 1888-1895.

18. Frongillo EA \& Wolfe WS (2010) Impact of participation in Home-Delivered Meals on nutrient intake, dietary patterns, and food insecurity of older persons in New York state. J Nutr Elder 29, 293-310.

19. Kelaiditi E, van Kan GA \& Cesari M (2014) Frailty: role of nutrition and exercise. Curr Opin Clin Nutr Metab Care 17, 32-39.

20. Bartali B, Frongillo EA, Guralnik JM et al. (2008) Serum micronutrient concentrations and decline in physical function among older persons. JAMA 299, 308-315.

21. Bartali B, Frongillo EA, Stipanuk MH et al. (2012) Protein intake and muscle strength in older persons: does inflammation matter? I Am Geriatr Soc 60, 480-484.

22. Rivera-Marquez JA, Mundo-Rosas V, Cuevas-Nasu L et al. (2014) Food insecurity at the household level and nutritional status of older people in Mexico. Salud Publica Mex 56, Suppl. 1, S71-S78.

23. Gutierrez JP, Rivera-Dommarco J, Shamah-Levy $\mathrm{T}$ et al. (2012) Encuesta Nacional de Salud y Nutrición 2012. Resultados Nacionales. Cuernavaca, Morelos: Instituto Nacional de Salud Pública.

24. Searle SD, Mitnitski A, Gahbauer EA et al. (2008) A standard procedure for creating a frailty index. BMC Geriatr $\mathbf{8}, 24$.

25. García-González JJ, García-Peña C, Franco-Marina $\mathrm{F}$ et al. (2009) A frailty index to predict the mortality risk in a population of senior Mexican adults. BMC Geriatr 9, 47.

26. Villagomez-Ornelas P, Hernandez-Lopez P, Carrasco-Enriquez B et al. (2014) Statistical validity of the Mexican Food Security Scale and the Latin American and Caribbean Food Security Scale. Salud Publica Mex 56, Suppl. 1, S5-S11.

27. Vilar-Compte M, Bernal-Stuart A, Orta-Alemán D et al. (2014) Is the Latin American and Caribbean food security scale an appropriate instrument for Mexican urban older adults? J Frailty Aging 3, 173-179.

28. Gobbens RJ, van Assen MA, Luijkx KG et al. (2011) Testing an integral conceptual model of frailty. J Adv Nurs 9, 2047-2060.

29. Rockwood K, Andrew M \& Mitnitski A (2007) A comparison of two approaches to measuring frailty in elderly people. J Gerontol A Biol Sci Med Sci 62, 738-743.

30. Wolfe W, Frongillo E \& Valois P (2003) Understanding the experience of food insecurity by elders suggests ways to improve its measurement. J Nutr 133, 2762-2769.

31. To QG, Frongillo EA, Gallegos D et al. (2014) Household food insecurity is associated with less physical activity among children and adults in the US population. J Nutr 144, 1797-1802.

32. Sahyoun NR \& Vaudin A (2014) Home-delivered meals and nutrition status among older adults. Nutr Clin Pract 29, 459-465.

33. Frongillo EA, Isaacman TD, Horan CM et al. (2010) Adequacy of and satisfaction with delivery and use of home-delivered meals. J Nutr Elder 29, 211-226.

34. Secretaría de Desarrollo Social (2015) Cruzada contra el hambre. http://www.gob.mx/sedesol/acciones-y-programas/ cruzada-nacional-contra-el-hambre-18938 (accessed May 2015).

35. Consejo Nacional de Evaluación de la Política de Desarrollo Social (2010) Informe de Evolución Histórica de la Situación Nacional de la Población y los Programas de Alimentación, Nutrición y Abasto en México. México, DF: CONEVAL.

36. Kim K \& Frongillo EA (2009) Patterns of food insecurity and participation in food assistance programmes over time in the elderly. Public Health Nutr 12, 2113-2119.

37. Gollub EA \& Weddle DO (2004) Improvements in nutritional intake and quality of life among frail homebound older adults receiving home-delivered breakfast and lunch. J Am Diet Assoc 104, 1227-1235. 